\title{
ROMANISCHE SPRACHWISSENSCHAFT
}

von

D R. H E I N R C H LA U S E R G

o. Professor der romanischen Philologie an der Universität Müncter

FORMENIEHRE/ TRSTER TEIT.

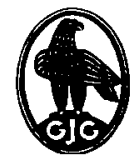

WALTER DE GRUY'TER \& CO.

vormals G. J. Göschen'sche Verlagshandlung · J. Guttentag, Verlagsbuchbandlung - Georg Reimer - Karl J. Trübner - Veit \& Comp. B E R L I N 1962 
Die Gesamtdarstellung umfaßt folgende Bände:

I. Einleitung und Volkalismus (Slg. Göschen Band 128/128 a)

II. Konsonantismus (Slg. Göschen Band 250)

III. Formenlehre / 1. Teil (Slg. Göschen Band 1199)

Formenlehre / 2. Teil (Slg. Göschen Band 1200/1200a)

IV. Wortlehre und Syntax (in Vorbereitung)

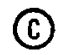

Copyright 1962 by Walter de Gruyter \& Co, vormals G. J. Göschen'sche Verlagshandlung - J. Guttentag, Verlagsbuchhandlung - Georg Reimer Karl J. Trübner - Veit \& Comp., Berlin W 30. - Alle kechte, einschl dor Rechte der Herstcllung von Photokopien und Mikrofilmen, von der Verlagshandlung vorbehalten. - Archiv-Nr. 7360622. - Satz und Druck: Walter de Gruyter \& Co., Berlin W 30, - Printed in Germany. 